\title{
The Convergence between Content and Access: Internalizing the Market Complementarity
}

\author{
NICOLAS CURIEN
}

\begin{abstract}
Autorité de Régulation des Communications Electroniques et des Postes and Laboratoire d'Econométrie, Conservatoire National des Arts et Métiers

FRANÇOIS MOREAU *
\end{abstract}

Laboratoire d'Econométrie, Conservatoire National des Arts et Métiers

\begin{abstract}
Developing a simple model of the content and access industries in the digital era, we show that, given the positive consumption externality from entertainment content (music, video) on access networks and playing devices (fixed broadband, $3 \mathrm{G}$ mobile, digital players, etc.), both content and access industries have an interest in blurring their business frontiers. As digital piracy, which is still increasing the above externality, benefits access providers to the detriment of content providers, a "win-win" game is possible only if access providers participate in content production, either through a subsidy or co-production.
\end{abstract}

\section{Introduction}

The consumption of digital content, for instance a song or a movie downloaded from an online platform (legal or illegal) or through a mobile network, requires the prior acquisition of an access technology, such as broadband internet access and a personal computer, a 3G mobile subscription and suitable handset, a MP3 digital player, etc. Hence, by releasing high quality and diversified musical or video contents, content providers ${ }^{1}$ generate a positive consumption externality and bring value to the access markets. However, content providers are encountering growing difficulties, given the severe downturn their markets are experiencing. On a retail price basis, the world recorded music

\footnotetext{
* Contact Author. Laboratoire d'Econométrie, Conservatoire National des Arts Métiers, Case 153, 2 rue Conté, 75003 Paris, France. Email: moreauf@cnam.fr The authors would like to thank Eric Brousseau and Thierry Pénard as well as two anonymous referees for their helpful comments.

${ }^{1}$ To simplify, we use the term "content providers" to cover firms such as music publishers - who hold the Intellectual Property (IP) rights - and labels, movie publishers and producers and even TV networks when they co-produce content.
} 
market has decreased by about $20 \%$ between 2000 and $2006^{2}$, and 2006 stands as the second successive declining year for world DVD retail and rental markets.

Digitization nearly transforms digital content into public goods. Non-rivalry comes from a zero reproduction (marginal) cost while excludability, that is, deterring free access to content (piracy), proves to be extremely problematic, both legally and technically 3 : neither lawsuits nor DRM (Digital Rights Management) systems, that prevent the unrestricted copying of digital products, prove to be efficient. In addition to the fact that some internet users find it quite easy to break them, DRM systems are being increasingly criticized, even by music rights holders such as small independent music labels, because they reduce the utility of legal users. As far as legal proceedings are concerned, the opinion is divided. According to Bhattacharjee et al (2006), lawsuits against pirates and against firms that produce peer-to-peer (P2P) software have no significant impact. Although the International Federation of the Phonographic Industry (2007) considers that legal actions have achieved some results, because the number of music files shared on P2P networks is believed to have decreased recently, this may only reflect a change in pirates' behavior: more and more internet users belong to private P2P networks, furthermore, the new generation of $\mathrm{P} 2 \mathrm{P}$ software are Open Source, and some of them even ensure user anonymity.

If content providers are weakened by digitization, the situation of access providers seems much more favorable. As already mentioned, digital content generates a positive consumption externality onto access markets. Moreover, whereas digital content exhibits characteristics of public goods, products and services sold in the access markets are private goods, both rival and excludable. Through managing the quality of their product, access providers can price discriminate their consumers and/or vertically differentiate their products. Thus, opportunities to extract consumer surplus are numerous. Finally, the relative size of access markets as compared to content markets (see table 1), as well as the bigger average size of access providers, gives the latter a-priori bargaining power over content providers. Hence, the complementary between the content and access industries, that is, the so-called "convergence", turns out to be more profitable to the latter than to the former.

\begin{tabular}{|l|l|l|l|}
\hline Content markets & Billion USD & Access markets & Billion USD \\
\hline Recorded music (a) & 30 & Mobile phone subscription (b) & 616 \\
\hline $\begin{array}{l}\text { VHS/DVD purchase and } \\
\text { rental (c) }\end{array}$ & 52 & Mobile phone handsets (b) : & 117 \\
\hline Movie theatres (d) & 23 & Internet Access (b) & 204 \\
\hline & $\begin{array}{l}\text { Video and audio portable } \\
\text { players (e) }\end{array}$ & 7 \\
\hline
\end{tabular}

Table 1: Relative size of content and access markets (2006 world sales).

Source: (a) Ifpi; (b) Idate; (c) Screen Digest (2005 data); (d) MPAA (2005 data); (e) Informa Telecoms \& Media (2005 data)

\footnotetext{
${ }^{2}$ Source: International Federation of the Phonographic Industry.

${ }^{3}$ See Peitz and Waelbroeck (2006a) for a comprehensive survey on piracy of digital products.
} 
For network operators (mobile $3 \mathrm{G}$ and fixed broadband), distributing content is an opportune new path of growth, given the decline in voice revenues induced by fiercer market competition and the rise of VoIP (Curien and Moreau, 2006a). Content obtained in violation of IP laws has almost certainly made a significant contribution to the explosive growth in access markets. Manufacturers of digital players strongly depend on the availability of attractive content, as do, to a lesser extent, internet access providers and $3 \mathrm{G}$ mobile network operators and handsets producers. On the other hand, digitalization has not yet created an online legal market for content large enough to compensate content providers for the shrinking of their offline distribution markets.

In this paper, our aim is to examine the ability of firms in the access markets to take best advantage of the distribution of content through their technologies. In a context where the efficient marginal prices of content are drastically driven downwards by digitalization and by the correlative reduction in marginal cost, the questions we raise are: should access providers participate in recovering the fixed costs involved in the production of content? Should they co-produce content? The paper is organized as follows. After modeling the content/access "convergence" and showing the existence of a "win-win" equilibrium in a stylistic game between a content provider and an access provider (section 2), we discuss our assumptions and results with regards to the policy recommendations that they suggest, as well as their consistency with empirical facts (section 3). We conclude with some proposals for developing our model, with the objective of a more comprehensive understanding of the industrial organization issues raised by convergence.

\section{The model}

\section{$2.1 \quad$ The content side}

A content provider supplies content in a monopoly situation ${ }^{4}$. Potential consumers form a population of size 1 . They are differentiated with respect to their taste $\theta$ for content consumption, where $\theta$ is uniformly distributed over the interval $[0,1], \theta=0$ (resp. $\theta=1$ ) being the individual who yields the greatest (respectively smallest) utility from the content consumption. Through his choice of quality $\theta_{k}$, that may be either low, $\theta_{0}$, or high, $\theta_{1}$ (with $\left.0<\theta_{0}<\theta_{1} \leq 1\right)$, the content provider makes his specific content more or less attractive to consumers. Precisely, he converts taste $\theta$ into willingness to pay $w_{k}(\theta)$, generating the pattern $w_{k}(\theta)=\sup \left(\theta_{k}-\theta, 0\right)(\theta \in[0,1])$. For the sake of simplicity, we assume that the cost $F_{k}$ incurred by the content provider depends only on quality $\theta_{k}$ with $F_{0}<F_{1}$.

If the content price is set at $p \leq \theta_{k}$ and if the piracy rate is $\tau$, then among the regular consumers, whose size is $1-\tau$, only those who are willing to pay more than $p\left(\theta_{k}-\theta \geq p\right.$ $\Rightarrow \theta \leq \theta_{k}-p$ ) actually buy the content, so that the "legal demand" is:

$$
d_{k, \tau}^{L}(p)=(1-\tau) \int_{0}^{\theta_{k}-p} d \theta=(1-\tau)\left(\theta_{k}-p\right)
$$

yielding the consumption surplus:

\footnotetext{
${ }^{4}$ Since the merger between CanalSat and TPS in the market of pay-TV, this is pretty much the prevailing situation in France for movies and the broadcasting of sports events.
} 
(2)

$S_{k, \tau}^{L}(p)=(1-\tau) \int_{0}^{\theta_{k}-p}\left(\theta_{k}-\theta-p\right) d \theta=(1-\tau) \cdot \frac{\left(\theta_{k}-p\right)^{2}}{2}$

As individuals lying between $\theta_{k}$ and 1 on the demand segment do not consume the content, even if it is free, the "illegal demand" arising from pirates is:

(3) $d_{k, \tau}^{P}=\tau \cdot \theta_{k}$,

yielding the surplus:

(4) $s_{k, \tau}^{P}=\tau \cdot \frac{\theta_{k}^{2}}{2}$.

Note that parameter $\theta_{k}$ is also the maximal market audience reached at price $p=0$ :

$$
\theta_{k}=d_{k, \tau}^{L}(0)+d_{k, \tau}^{P}
$$

\subsection{The access side}

We assume that consumers, whether legitimate or pirate, devote a share $\rho(0<\rho \leq 1)$ of the surplus they expect from their content consumption $\left(s_{k, \tau}^{L}(p)\right.$ or $\left.s_{k, \tau}^{P}\right)$ to purchasing one or more of several competing access technologies such as ADSL, cable or 3G mobile subscriptions, digital players, etc. This amounts to making two reasonable assumptions. First, the decision to purchase access technologies is seen as a consequence rather than a cause of content consumption; and second, an increase in the surplus derived from content raises demand in the access market. Indeed, empirical evidence shows that pirates, since they obtain a large surplus from (non-rival) digital content consumption, highly value (and duly pay for) the (rival) goods supplied by the access industry ${ }^{5}$.

Since quality and price in the market for content directly influence the surplus that consumers draw from content, they indirectly drive revenues in the access markets. The parameter $\rho$, which governs this process, reflects the intensity of a positive externality from content on access ${ }^{6}$.

In this very simple model, we do not take into account the features of horizontal competition between the various access providers and we simply consider overall access as an aggregate downstream market related to the upstream monopoly of content. An alternative interpretation of our model is to consider one particular access provider in isolation dealing individually with the upstream monopoly. Whatever the interpretation, we shall designate the unique or aggregate firm in the access segment as "the access provider". We shall further assume that the cost incurred for providing access is a pure fixed cost $G$.

\subsection{First best optimum}

From the consumers' distribution of tastes, we derive the expression of the net social welfare, that is, the difference between the aggregate willingness to pay for content and access, on the one hand, and aggregate cost on the other:

\footnotetext{
${ }^{5}$ See the strong growth experienced by the broadband Internet access market, the market for mobile phone handsets that play music, and also the digital player market.

${ }^{6}$ Note that the level of $\rho$ also depends in part on the intrinsic vitality of the access market, that is, the ability of actors in that market to convert consumers' willingness to pay into actual revenues.
} 


$$
S_{k}=\int_{0}^{\theta_{k}} \theta \cdot d \theta-F_{k}-G=\frac{\theta_{k}^{2}}{2}-F_{k}-G
$$

Assuming that:

$$
\frac{\theta_{1}^{2}}{2}-F_{1}>\frac{\theta_{0}^{2}}{2}-F_{0}>G
$$

then maximizing $S_{k}$ with respect to $\theta_{k}$ yields the first best quality $\theta_{k}{ }^{*}$ and the maximal social welfare $S^{*}$, that is:

$$
\theta_{k}^{*}=\theta_{1} \quad S^{*}=S_{1}=\frac{1}{2} \theta_{1}^{2}-F_{1}-G
$$

It should be noted that the optimal social welfare does not depend on the piracy rate $\tau$. This derives from the fact that the first best price of content is trivially $p^{*}=0$, since the marginal cost is zero. Thus, at the first best optimum, high-quality content is freely distributed. The value generated by this content is not collected directly in the upstream content market, but indirectly in the downstream access market, attracting a large audience because of the high quality and low price of content.

However, the first best optimum is a pure theoretical benchmark, because the two market components of content and access are driven by players who have conflicting interests, namely the content provider in the former market, and the access provider in the latter. Before considering the strategic game between those two firms, let us first examine their respective profit functions.

\subsection{Profit functions}

To simplify, we assume that the revenues derived in the content market go exclusively to the content provider, an assumption which does not misrepresent reality, since the fraction of content revenues kept by access providers has, up until now, been insignificant. As for revenues derived in the access market, a share of them is supposed to be retroceded to the content provider: more precisely, $\rho$ being the share of consumer surplus which is actually converted into purchasing access (see above), a sub-share $\sigma(0 \leq \sigma \leq \rho)$ is used by the access provider to subsidize or even to invest in content production. The parameter $\sigma$ then represents the "co-production rate" 7 .

The co-production rate $\sigma$ stands as a key strategic variable in the relationship between a content provider and an access provider. Case $\sigma=0$ correctly reflects the present situation of "revenue separation", where content providers draw their profits from content sales while access providers keep all access revenues.

Introducing the price/quality index of content, that is, the ratio of nominal price over quality:

$$
\pi=p / \theta_{k},
$$

and then aggregating direct revenues from sales and indirect revenues from co-production, the content provider's global profit is:

$$
P_{k, \tau \sigma}(\pi)=(1-\tau) \cdot p\left(\theta_{k}-p\right)+\sigma \cdot\left(s_{k, \tau}^{L}(p)+s_{k, \tau}^{P}\right)-F_{k}
$$

\footnotetext{
${ }^{7}$ Note that the capture by the content provider of part of the consumers' surplus is similar to price discrimination, because an individual's global payment to the content provider increases with his willingness to pay.
} 


$$
\begin{aligned}
& =\left((1-\tau) \cdot \pi(1-\pi)+\frac{\sigma}{2} \cdot\left[(1-\tau) \cdot(1-\pi)^{2}+\tau\right]\right) \cdot \theta_{k}^{2}-F_{k} \\
& =\left[-(1-\tau) \cdot(2-\sigma) \cdot \pi^{2}+2(1-\tau)(1-\sigma) \cdot \pi+\sigma\right] \cdot \frac{\theta_{k}^{2}}{2}-F_{k} .
\end{aligned}
$$

Setting:

$$
f_{\tau, \sigma}(\pi) \equiv-(1-\tau)(2-\sigma) \cdot \pi^{2}+2(1-\tau)(1-\sigma) \cdot \pi+\sigma,
$$

we finally derive:

$$
P_{k, \tau, \sigma}(\pi)=f_{\tau, \sigma}(\pi) \cdot \frac{\theta_{k}^{2}}{2}-F_{k}
$$

Similarly, the access provider's profit is:

$$
A_{\rho, k, \tau, \sigma}(\pi)=(\rho-\sigma) \cdot\left[(1-\tau) \cdot(1-\pi)^{2}+\tau\right] \cdot \frac{\theta_{k}^{2}}{2}-G
$$

We now assume that the content and access providers enter a two-player strategic game, in which the content provider plays second, maximizing his profits with respect to the content quality $\theta_{k}$ and price $p$ (or equivalently with respect to $\theta_{k}$ and $\pi$ ), at a given coproduction rate $\sigma$; while the access provider plays first as a Stackelberg leader ${ }^{8}$, selecting $\sigma$ so as to maximize his profit while anticipating the impact of his $\sigma$-decision on the content quality $\theta_{k}$ and price $p$ that will consequently be selected by the content provider. To solve the game by backward induction, we begin by examining the second stage, that is, the maximization of the content provider's profit.

\subsection{Maximization of the content provider's profit}

The function $f_{\tau, \sigma}(\pi)$ is concave (because the coefficient of $\pi^{2}$ is negative), so the first-order condition for the maximization of $P_{k, \tau, \sigma}(\pi)$ with respect to $\pi$ yields the profit maximizing relative price of content:

(10) $\pi_{\sigma}=1-\frac{1}{2-\sigma}$.

Hence, the price/quality index $\pi_{\sigma}$ is a decreasing function of the co-production rate $\sigma$, with $\pi_{1}=0$, but it does not depend on the piracy rate. Very logically, the larger the share of access revenues the content provider can obtain from co-production, the more revenues from selling content he is ready to forego, through a price-cut aimed at boosting the access market. Further, the nominal price $p_{\tau, \sigma}$ of content falls together with quality $\theta_{\tau, \sigma}$ when piracy $\tau$ develops, so as to maintain the ratio $\pi_{\sigma}=p_{\tau, \sigma} / \theta_{k, \sigma}$ constant when $\tau$ varies (see below).

Let us introduce:

$$
f_{\tau, \sigma}=f_{\tau, \sigma}\left(\pi_{\sigma}\right)=\frac{1-\tau}{2-\sigma}+\tau . \sigma=\frac{1-\tau(1-\sigma)^{2}}{2-\sigma},
$$

satisfying:

\footnotetext{
${ }^{8}$ As we have already mentioned, piracy harms content providers while benefiting access providers because pirated content increases consumer willingness to pay in access markets. Access providers could thus be considered to have a higher bargaining power than content providers when negotiating how the access market could compensate the content market.
} 


$$
\frac{\partial f_{\tau, \sigma}}{\partial \tau} \leq 0, \quad \frac{\partial f_{\tau, \sigma}}{\partial \sigma} \geq 0, \quad 0=f_{1,0} \leq f_{\tau, \sigma} \leq f_{\tau, 1}=1 .
$$

Then, the price-optimized content provider's profit can be stated as:

(11) $P_{k, \tau, \sigma}=f_{\tau, \sigma} \cdot \frac{\theta_{k}^{2}}{2}-F_{k}$.

Denoting:

$$
\varphi=2 \cdot \frac{F_{1}-F_{0}}{\theta_{1}^{2}-\theta_{0}^{2}}<1,
$$

we can easily derive the profit-maximizing quality $\theta_{k \tau, \sigma}$ and the profit-maximizing nominal price $p_{\tau, \sigma}$ :

$$
\begin{aligned}
& 0 \leq f_{\tau, \sigma} \leq \varphi \Rightarrow \theta_{k, \sigma}=\theta_{0} \Rightarrow p_{\tau, \sigma}=\pi_{\sigma} . \theta_{0} \\
& \varphi \leq f_{\tau, \sigma} \leq 1 \Rightarrow \theta_{k \tau, \sigma}=\theta_{1} \Rightarrow p_{\tau, \sigma}=\pi_{\sigma} . \theta_{1},
\end{aligned}
$$

and finally, the expression of the content provider's overall maximized profit is:

$$
P_{\tau, \sigma}=\left\{\begin{array}{l}
f_{\tau, \sigma} \cdot \frac{\theta_{0}^{2}}{2}-F_{0} \text { if } 0 \leq f_{\tau, \sigma} \leq \varphi \\
f_{\tau, \sigma} \cdot \frac{\hat{\theta}_{1}^{2}}{2}-F_{1} \text { if } \varphi \leq f_{\tau, \sigma} \leq 1
\end{array}\right.
$$

$f_{\tau, \sigma}$ thus represents the

joint impact of the piracy rate and the co-production rate on the content provider's profits. We can now state the following proposition:

Proposition 1 At a high enough piracy rate $\tau$ or a low enough co-production rate $\sigma$ (that is, at values of $\tau$ and $\sigma$ such that $\left.f_{\tau, \sigma} \leq \varphi\right)$, the quality of content $\theta_{k, \sigma}=\theta_{0}$ is lower than its first best level $\theta_{k}^{*}=\theta_{1}$.

As previously noted, the nominal price $p_{\tau, \sigma}$ of content decreases with respect to the piracy rate $\tau$. The nominal price also decreases with respect to the co-production rate $\sigma$, with, however, a discontinuous positive jump along the frontier $f_{\tau, \sigma}=\varphi$ (for $f_{\tau, \sigma}=\varphi^{+}$the nominal price is higher than for $f_{\tau, \sigma}=\varphi^{-}$). It reaches its first best level $p^{*}=0$ only when $\sigma=\rho=1$, that is, when the content provider internalizes the whole consumer surplus (maximizing profit then amounts to maximizing welfare).

\subsection{Equilibrium and comparative statics}

From now on, we shall assume the parametric conditions:

$$
\frac{1}{2} \leq \varphi=2 \cdot \frac{F_{1}-F_{0}}{\theta_{1}^{2}-\theta_{0}^{2}} \leq \rho \leq 1 \quad, \quad F_{1} / \theta_{1}^{2}>F_{0} / \theta_{0}^{2}
$$

requiring that the global return $\theta_{k}^{2} / 2 F_{k}$ on quality is decreasing $\left(\theta_{1}^{2} / 2 F_{1}>\theta_{0}^{2} / 2 F_{0}\right)$, the incremental return $1 / \varphi\left(\theta_{1}^{2} / 2 F_{1}-\theta_{0}^{2} / 2 F_{0}\right)$ is not too high, and the market externality $\rho$ is high enough. 
Anticipating the profit maximizing behavior of the content provider, that is, $\pi=$ $\pi_{\sigma}=1-\frac{1}{2-\sigma}$ and $\theta_{k}=\theta_{k \tau, \sigma}$, the access provider selects the co-production rate $\sigma$ so as to maximize his profit:

$$
A_{\rho, \tau, \sigma}=(\rho-\sigma) \cdot\left[\frac{1-\tau}{(2-\sigma)^{2}}+\tau\right] \cdot \frac{\theta_{k, \sigma}^{2}}{2}-G
$$

Because $A_{\rho, \tau, \sigma}$ is a decreasing function of $\sigma$ at given $\theta_{\tau, \sigma}$ (it is a linear combination of the two decreasing functions $\rho-\sigma$ and $\left.(\rho-\sigma) /(2-\sigma)^{2}\right)$, the access provider has to compare only two strategies. Either not contributing to content production $(\sigma=0)$, then getting the low level of quality $\theta_{k \tau, 0}=\theta_{0}$ from the content provider $\left(\right.$ since $\left.f_{\tau, 0}=(1-\tau) / 2<1 / 2<\varphi\right)$ and earning:

$$
A_{\rho, \tau, 0}=\rho \cdot(1+3 \tau) \cdot \frac{\theta_{0}^{2}}{8}-G
$$

or contributing, at the smallest co-production rate $\sigma_{\varphi, \tau}$ that gives the content provider an incentive to select the high quality level $\theta_{k \tau, \sigma \varphi, \tau}=\theta_{1}$, that is, at rate $\sigma_{\varphi, \tau}$ satisfying $f_{\tau, \sigma \varphi, \tau}=\varphi^{9}$ :

$$
\begin{gathered}
\sigma_{\varphi, \tau}=1-2 \cdot \frac{1-\varphi}{\varphi+\sqrt{\varphi^{2}+4(1-\varphi) \cdot \tau}} \\
0 \leq 2-\frac{1}{\varphi}=\sigma_{\varphi, 0} \leq \sigma_{\varphi, \tau} \leq \sigma_{\varphi, 1}=\varphi \leq \rho,
\end{gathered}
$$

yielding the profit:

$$
A_{\rho, \tau, \sigma \varphi, \tau}=\left(\rho-\sigma_{\varphi, \tau}\right) \cdot\left[\frac{1-\tau}{\left(2-\sigma_{\varphi, \tau}\right)^{2}}+\tau\right] \cdot \frac{\theta_{1}^{2}}{2}-G
$$

We shall now make the assumption that the ratio $\theta_{0} / \theta_{l}$, reflecting the loss in market audience due to a reduction in content quality (from $\theta_{k}=\theta_{1}$ to $\theta_{k}=\theta_{0}$ ), lies under a threshold such that the access provider always prefers the co-production strategy, whatever the piracy rate $\tau\left(A_{\rho, \tau, 0}<A_{\rho, \tau, \sigma, \tau, \tau}\right.$ for any $\left.\tau \in[0,1]^{10}\right)$. Equilibrium is then characterized as follows.

At equilibrium, content quality is set by the content provider at its first best level $\left(\theta_{k}{ }^{*}=\right.$ $\left.\theta_{1}\right)$, while the co-production rate $\sigma_{\varphi, \tau}$ selected by the access provider is strictly positive and increasing with respect to the piracy rate $\tau$ : the more piracy develops, the more the access provider must participate in content production in order to keep quality high, a

\footnotetext{
${ }^{9}$ Note that, in the case of high returns on quality $(\varphi<1 / 2)$, a situation which we have excluded, then with small rates of piracy $(0 \leq \tau \leq 1-2 \varphi)$, the high level of quality would be obtained by the access provider in the absence of any co-production $\left(\theta_{\tau, 0}=\theta_{1}\right)$. But were piracy to exceed threshold $1-2 \varphi$, then co-producing at rate $\sigma_{\varphi, \tau}>0$ would become necessary to obtain high quality content, just as in the case $\varphi \geq 1 / 2$ that we examine here.

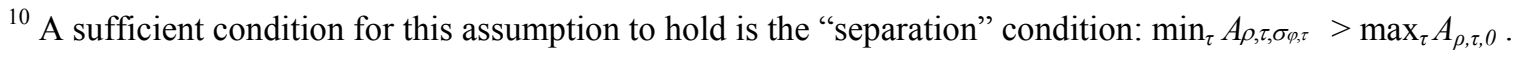
As the "min" is reached at $\tau=0$ whatever $\rho>\varphi$ (as can easily be checked by studying the variations of $A \rho, \tau, \sigma \varphi, \tau$ with respect to $\tau$ ) and as the "max" is trivially reached at $\tau=1$, then the "separation" condition can be stated as $(\rho-2+1 / \varphi) \varphi^{2} \theta_{1}^{2} / 2>\rho \theta_{0}^{2} / 2$, that is : $\theta_{0}^{2} / \theta_{1}^{2}<\varphi / \rho$. [1- $\left.\varphi(2-\rho)\right]$. Note that the right-hand side of the above inequality is both positive (as $\rho>\varphi>2-1 / \varphi>0$ ) and less than 1 (as $\varphi / \rho<1$ and $\rho<1$ ).
} 
participation which maintains the content provider's profit at a constant level, making him indifferent to piracy:

(17) $P_{\tau, \sigma \varphi, \tau}=\varphi \cdot \frac{\theta_{1}^{2}}{2}-F 1=\frac{F 1 \theta_{0}^{2}-F 0 \theta_{1}^{2}}{\theta_{1}^{2}-\theta_{0}^{2}}>0$.

Simple calculations finally lead to the following proposition:

Proposition 2 The access provider's profit is either increasing with respect to the piracy rate $\tau$ over interval $[0,1]$, or increasing and then decreasing, depending on the market externality level $\rho$. More precisely, the maximum of $A_{\rho, \tau, \sigma \varphi, \tau}$ is reached at $\tau=\tau_{\rho, \varphi}$ with:

$$
\begin{aligned}
& \tau_{\rho, \varphi}=1 \text { if } \frac{2}{3-\varphi} \leq \rho \leq 1 \\
& \tau_{\rho, \varphi}=\frac{\left((2-\varphi) \sqrt{1-\frac{2-\rho(3-\varphi)}{2(1-\rho)(2-\varphi)}}-1+\varphi\right)^{2} \cdot\left(2-\frac{\varphi[2-\rho(3-\varphi)]}{(1-\varphi)^{2}}\right)}{2+\varphi(2-\rho)\left[\sqrt{1+\frac{2-\rho(3-\varphi)}{(2-\rho)(1-\varphi)}}-1\right]}<1 \\
& \text { if } \varphi \leq \rho \leq \frac{2}{3-\varphi} .
\end{aligned}
$$

As a consequence, provided the positive externality from content on access lies below a certain threshold, then access providers should not encourage unregulated $\mathrm{P} 2 \mathrm{P}$, wisely anticipating that their own revenues would eventually decline if they had to compensate rights holders for the damages of piracy. ${ }^{11}$

\section{Discussion}

\subsection{Policy recommendations}

One of the main contributions of this paper is to shed new light on the way public policy should deal with piracy. The debate on this topic usually sets contributions, both theoretical and empirical, suggesting that piracy may have a positive impact on content markets through a sampling effect, because P2P users may buy an original content they had first downloaded as a low-quality copy (Peitz and Waelbroeck, 2006b; and Bounie et al, 2006), against papers arguing that piracy undoubtedly harms content providers (see for instance Liebowitz, 2006). We show in this paper that consideration of the complementarity between content and access markets enlarges the piracy debate, and that piracy may have an overall positive impact on social welfare quite apart from the sampling effect.

\footnotetext{
${ }^{11}$ In particular, this could account for the currently observed virtuous behavior of Internet access providers in France, who were initially accused of boosting piracy by explicitly founding their campaigns for broadband Internet subscriptions on the free access to content: they have now modified their marketing strategy and (supposedly) tried to deter the use of P2P networks.
} 
As highlighted in footnote 9, when returns on quality are high and the piracy rate is low, a content provider spontaneously produces high-quality content, so that the coproduction rate is then equal to zero. In such a context, a marginal increase in the piracy rate harms content providers but benefits access providers. This is a quite standard and expected result on the effects of piracy. However, when returns on quality are lower $(\varphi>$ $1 / 2$ in our model), content providers always prefer to produce low-quality content, and coproduction is therefore always needed to improve social welfare. Furthermore, if the positive market externality from content on access is large enough, nobody wins at fighting piracy. Content providers are indifferent to piracy because access providers subsidize them to produce high-quality content, and as far as the latter are concerned, although the coproduction rate increases with piracy, so does their profit. Consequently, giving incentives for the access market to subsidize the content market seems more relevant than fighting piracy. ${ }^{12}$

Finally, relaxing the hypothesis of a strong vertical differentiation of content (a low enough $\theta_{0} / \theta_{1}$ ratio in our model) and maintaining low returns on quality could prompt access providers to choose not to co-produce $(\sigma=0)$, while content providers produce lowquality content $\left(\theta_{k}=\theta_{0}\right)$, that is, not socially optimal. Once again, fighting piracy does not appear to be the best answer, because even when there is no piracy, content providers prefer low-quality content when $\sigma=0^{13}$. In such conditions, one solution could be to transform a discretionary co-production into a tax. In France, such a tax, paid by internet access providers to subsidize audiovisual production, is scheduled to be implemented.

Thus, consideration of the two complementary markets for content and access shows that when piracy benefits access providers, it is often in the latter's interest to co-produce content. When this is not the case, giving incentives to access providers to contribute to the production of high-quality content could be preferable to a policy of fighting piracy with very uncertain results.

\subsection{Empirical relevance}

In this section, we compare the model's predictions with empirical facts. Although it is beyond the scope of this paper to provide a comprehensive empirical analysis of access and content providers' strategies in the age of IT/internet/media technological convergence, many observations do show that ensuring content quality and availability has become a crucial stake for access providers.

As a matter of fact, convergence has increased the interest of access providers in content and some of them do invest upstream of their traditional market, like France Telecom, who created a content division in 2004 and announced in 2006 that the firm will co-produce between ten and fifteen movies each year. This fully corroborates the model's result about access providers' fear of a shortfall in the quality of content and the use of coproduction as an incentive to maintain high quality. In the music industry, Microsoft has agreed to retrocede two dollars to Universal Music for every Zune digital player purchased, implicitly acknowledging that legal digital music would probably not represent a large share of the average content of a Zune. Indeed, according to Steve Jobs, Apple's

\footnotetext{
${ }^{12}$ However, for sufficiently low values of $\rho$, that is when the positive externality from content on the access market is not too large, it is in the interest of access providers to prevent widespread piracy. It would be too costly for them to subsidize the content market to secure the production of high-quality content, given the expected return on the access market.

${ }^{13}$ If $\sigma=0, f_{\tau, 0}=(1-\tau) / 2$ and $\varphi \geq 1 / 2$ implies that $\forall \tau, f_{\tau, 0} \leq \varphi$ and thus $\theta_{k \tau, 0}=\theta_{0}$.
} 
CEO, legally purchased music does not represent more than $3 \%$ of all music uploaded on iPods.

Another method access providers have for subsidizing the content market is to transform the two complementary markets for content and access into a genuine two-sided market $^{14}$ and play as intermediaries between content providers and consumers, by investing in platforms that aggregate and sell content. Then, by agreeing to pay content above the market price, platforms effectively pay subsidies to content providers, and an outcome very similar to content co-production may be obtained. Below we give some of the most relevant examples of such an evolution towards a two-sided market framework for access to content ${ }^{15}$ :

- Revenues that mobile operators or internet access providers guarantee to video or music publishers are quite attractive: as far as musical content is concerned, the margin that content providers make on online sales appears to be higher than on physical sales (Curien and Moreau, 2006b).

- Mobile operators provide "free music" options in their subscription offers or when selling new mobile handsets as a means of increasing the demand for highspeed mobile internet. MCA technology, a MP3 player producer, has secured a deal with Universal Music by which owners of the MCA's NEO digital player can download songs for free from the platform Buzzmusic.fr during six months. In the same vein, the new Microsoft digital player (Zune) will be pre-loaded with videos of EMI artists alongside those from other record companies. Such offers in the retail access market correspond to a positive value of the co-production rate $\sigma$ in our model, since the copyright holders receive payment for the "free" content.

- The entry of Apple into the online music market is also significant. Before launching iTunes Music Store, an online music platform in which music files are embedded with DRMs that prevent them from being played on digital players other than Apple's iPod, the Californian firm had first studied the opportunity of purchasing one of the five music majors in order to secure content. Eventually, Apple gave up with that option of vertical integration in favor of a two-sided market design where it could monitor prices on both sides: the retail price of online music and the price paid to content providers. Apple does not earn any money with this platform, a paradox considering its high market power in the online music market, with a $70 \%$ market share in the US and the UK. The explanation is simple. Subsidizing both content providers and consumers allows Apple to boost iPod sales, which generate most of the firm's profits. Similarly, Nokia announced in 2006 the acquisition of the online content distribution platform OD2; the $3 \mathrm{G}$ mobile handset manufacturer will thus be able to supply

\footnotetext{
${ }^{14}$ On two-sided markets, see, amongst others, Armstrong (2005), Rochet and Tirole (2006), and Roson (2005) for a survey.

${ }^{15}$ Note that the subsidized side of the market is systematically the content side (content providers being directly subsidized and/or the retail prices of content being set low), whereas the "money side" is always access. This confirms the assumption of the positive externality generated from the content industry on the access market.
} 
handsets together with content, the respective prices of the two complementary goods being set jointly and optimally.

However, such examples do not guarantee that these outcomes are optimal. On the one hand, however it materializes; the actual co-production rate is possibly suboptimal (see section 3.1). For instance, the amount Microsoft pays to Universal Music (and not to the recorded music industry as a whole) for each Zune digital player sold is more symbolic than a fair compensation for the positive externality the recorded music market generates on the digital players. On the other hand, content providers usually demand a larger contribution from access markets to content production, although they fear the entry of access providers into the content market because of their presumed unfavorable bargaining power. Content providers could thus prefer a contribution to content production deriving from a legal constraint. The fact that, in France, the tax for financing content is only levied on internet access providers is not trivial. Indeed, the fierce competition on the internet access market prevents firms from spontaneously contributing to content production. Conversely, in the more profitable markets of mobile telephony (both subscription and handsets) and digital players, access providers seem readier to contribute to content production. Finally, the sharing among content producers of revenues paid by access providers could turn out to be problematic. As far as piracy is concerned, should the sharing be based on CD sales (as it is for the revenues from the tax for private copy levied on blank CD or DVD sales and on hardware sales) or should it be based on actual download statistics? Furthermore, in the case of download statistics, some DRM systems now make it possible not only to assess how many times a song or a film are downloaded, but also how many times they are listened to or viewed. Should the sharing of revenues take into account this index of consumers' intensity of preferences?

\section{Conclusion}

Two paths of extension of our present model appear quite obviously.

Firstly, taking into account the two-way positive externality, not only from content on access, but also from access on content, would allow us to tackle the issue raised by the viability of upcoming optical fiber fixed networks or 3G (and $4 \mathrm{G}$ ) mobile networks. The latter offer an outlet to very high bandwidth content (such as VOD or TV programs in a HD standard, for instance) which cannot be supported with an acceptable quality of service on existing technologies. This could justify a subsidization of those new networks by content providers.

Secondly, the vertical and horizontal organizational features of the industrial content/access chain should be examined, with a particular focus on exclusive deals, that is, deals ensuring that given content is available on one single access network during a minimum period of time ${ }^{16}$. That issue is connected with the debate about net neutrality in the US, a debate with no clear-cut conclusions because of the ambiguous welfare effects. On the one hand, exclusivity is a way of stimulating the production of content by creating a vertical "revenue channel" from access to content, but on the other hand, the overall

\footnotetext{
${ }^{16}$ For instance, in October 2005, through a deal between France Telecom and Warner Music, Madonna's last single could be downloaded exclusively on France Telecom's fixed and mobile networks, before the national release a few weeks later.
} 
audience for content is reduced because of exclusivity, a horizontal effect harming the global business of access.

Exclusive deals, should they become widespread, could then lead to a prisoner's dilemma situation in which each operator would suffer from the exclusivities secured by his rivals. The positive cross-externality between content and access could even generate a negative spiral, restricted access to content leading to slower growth of both the content and the access markets. Given the natural inclination of access providers to subsidize content, as shown in this paper, it is far from certain that the net effect of exclusive deals on welfare would eventually be positive. However, in a country like France, where the degree of competition in the market for broadband access is rather high, the emergence of several competing vertical structures, resulting from exclusive deals or from vertical integration moves, should not lead to a dramatic welfare loss.

\section{$5 \quad$ References}

Armstrong, M. (2005) "Competition in Two-Sided Markets," Rand Journal of Economics, forthcoming.

Bhattacharjee, S., R.D. Gopal, K. Lertawachara and J.R. Marsden (2006) "Impact of Legal Threats on Online Music Sharing Activity: An Analysis of Music Industry Legal Actions," Journal of Law and Economics, 49: 91-114.

Bounie, D., M. Bourreau and P. Waelbroeck (2006) "Pirates or Explorers: Analysis of Music Consumption in French Graduate Schools", mimeo, ENST, Paris.

Curien, N. and F. Moreau (2006a) L'industrie du disque à l'heure de la convergence télécoms/médias/internet. In X. Greffe (ed), Création et diversité au miroir des industries culturelles. Paris: La Documentation Française.

Curien, N. and F. Moreau (2006b) L'industrie du disque. Paris: La Découverte.

International Federation of Phonographic Industry (2007) "Digital Music Report", http://www.ifpi.org/content/library/digital-music-report-2007.pdf

Liebowitz, S.J. (2006) Economists Examine File-Sharing and Music Sales. In G. Illing \& M. Peitz (ed.), Industrial Organization and the Digital Economy. MIT Press: Cambridge.

Peitz, M. and P. Waelbroeck (2006a) "Piracy of Digital Products: A Critical Review of the Economics Literature," Information Economics and Policy, 18: 449-476.

Peitz, M. and P. Waelbroeck (2006b) "Why the Music Industry May Gain from Free Downloading - the Role of Sampling," International Journal of Industrial Organization, 24: 907-914.

Rochet, J.C. and J. Tirole (2006) "Two-Sided Markets: A Progress Report," Rand Journal of Economics, forthcoming. 
Roson, R. (2005) "Two-Sided Markets: A Tentative Survey," Review of Network Economics, 4: 142-160. 